\title{
GENÓTIPOS DE TOMATEIRO DO BANCO DE GERMOPLASMA DE HORTALIÇAS DA UFV RESISTENTES À PINTA PRETA
}

\author{
J.F.J. Grigolli, M.M. Kubota, D.P. Alves, G.B. Rodrigues, D.J.H. da Silva
}

Universidade Federal de Viçosa, Departamento de Fitotecnia, Av. P.H. Rolfs, s/no, CEP 36571-000, Viçosa, MG, Brasil. E-mail: jose_fernando_jg@yahoo.com.br

\section{RESUMO}

\begin{abstract}
A pinta preta do tomateiro é uma das principais doenças da cultura. Assim, o objetivo deste trabalho foi caracterizar 49 subamostras de tomateiro do Banco de Germoplasma de Hortaliças da Universidade Federal de Viçosa (BGH-UFV) quanto à pinta preta. O experimento ocorreu em Viçosa, MG, entre dezembro de 2007 e abril de 2008. Utilizou-se delineamento em blocos casualizados com três repetições e as testemunhas Débora, Fanny, Santa Clara e IPA-6. Realizaram-se cinco avaliações com base na severidade da doença. Com os valores de severidade calculou-se a área abaixo da curva de progresso da doença (AACPD), possibilitando uma melhor visualização dos resultados. Foi realizada a análise de variância, seguido do agrupamento das médias de AACPD pelo teste de Scott-Knott, a 5\% de significância. As subamostras BGH-2109, BGH-2110, BGH-2115, BGH-2122, BGH-2134, BGH-2135 e BGH-2142 apresentaram menor média de AACPD em relação às testemunhas, podendo ser utilizadas em futuros programas de melhoramento.
\end{abstract}

PALAVRAS-CHAVE: Alternaria solani, Solanum lycopersicum, recursos genéticos.

\section{ABSTRACT}

TOMATO GENOTYPES FROM BGH-UFV RESISTANT TO EARLY BLIGHT. Tomato early blight is one of the most important diseases of this crop. The aim of this study was to characterize 49 tomato sub-samples of the Vegetable Germoplasm Bank of the Universidade Federal de Viçosa (BGH-UFV) for early blight. The assay was carried out in Viçosa, Minas Gerais State, Brazil, between December 2007 and April 2008. The experimental design consisted of a randomized block with three replications and the controls Débora, Fanny, Santa Clara and Ipa-6. There were 5 evaluations based on the disease severity. With the severity values, the area under the disease progress curve (AUDPC) was calculated, enabling a better visualization of the results. Variance analysis was performed, followed by the grouping of the AUDPC averages by the Scott-Knott test at the 5\% significance level. The sub-samples BGH-2109, BGH-2110, BGH-2115, BGH-2122, BGH-2134, BGH-2135 and BGH-2142 had a lower AUDPC average in relation to the controls, and could be used in future breeding programs.

KEY WORDS: Alternaria solani, Solanum lycopersicum, genetic resources.

\section{INTRODUÇÃO}

O tomate, pertencente à família Solanaceae, é uma hortaliça de grande importância para o Brasil (TAMBARUSSi et al., 2009). Em 2010, a área plantada no Brasil foi de60.697 ha com uma produção de 3.595.548 toneladas (IBGE, 2010). O Estado de Minas Gerais é o segundo maior produtor desta hortaliça, com 7.339 ha plantados e produção de 474.998 toneladas (IBGE, 2010). No entanto, muitos fatores são responsáveis por perdas significativas, como pragas e doenças (SCHUElter et al., 2006).

Nesse cenário, a pinta preta do tomateiro causada pelo fungo Alternaria solani é uma das mais importantes e frequentes doenças fúngicas na cultura do tomateiro no Brasil (IтAKO et al., 2008). Em levantamento realizado em áreas cultivadas com tomate em Minas Gerais constatou-se que a pinta preta estava entre as doenças de maior incidência (88\%) e que as pulverizações com fungicidas durante o ciclo da cultura para controle dessa doença atingia 18 aplicações (VALE et al., 1992).

Esta doença ocorre sob várias condições climáticas, sendo mais severa em regiões com alta umidade relativa combinadas a altas temperaturas (FrITZ et al., 2006). Provoca redução da área fotossintética e, em casos severos, pode causar desfolha das plantas (ChAERANi et al., 2007). A ocorrência de epidemias severas da doença está associada à temperatura na faixa de 25 a $32^{\circ} \mathrm{C}$ e elevada umidade (Tófoli; 
DOMINGUES, 2005). À medida que a doença progride, formam-se anéis concêntricos nos órgãos afetados, bastante característicos dessa doença (FREITAS FILHO et al., 2008).

Embora a resistência genética seja o método de controle mais eficiente, ainda não há nenhuma variedade de tomate cultivada com alta resistência à pinta preta. MoretTo; Barreto (1997) e Tófoli; KurozaWA (1993) encontraram em alguns genótipos, como Ohio 4013, IPA-5 e IPA-6, altos níveis de resistência. Portanto, há uma necessidade de seidentificar novas fontes de resistência a este patógeno em razão da pressão de seleção efetuada sobre a população do patógeno quando se faz uso de um único cultivar.

A aplicação de fungicidas, tanto protetores quanto sistêmicos, consiste no principal método de controle dessa doença. Todavia, esses produtos ocasionam um incremento no custo de produção e são pouco efetivos em períodos de alta umidade (Holm et al., 2003). Além disso, os fungicidas são frequentemente utilizados em dosagens superiores à indicada, podendo provocar seleção de patógenos resistentes, contaminação ambiental e problemas de saúde para os trabalhadores e consumidores (BATISTA et al., 2006). Geralmente, esses fungicidas são aplicados sem considerar o desenvolvimento da doença ou se as condições epidemiológicas lhe são favoráveis (PAtTerson; NoKes, 2000).

Em programas de melhoramento os genitores podem ser selecionados a partir de cultivares antigos da espéciecultivada bem como das espécies silvestres pertencentes ao mesmo gênero que se encontram registrados nos bancos de germoplasma (VALLOIs et al.,1996). No entanto, menos de $8 \%$ dos recursos dos bancos de germoplasma são efetivamente utilizados pelos melhoristas (VALLOIS., 1998). Um dos principais fatores que concorrem para a pequena utilização de genitores nos programas de melhoramento está o desconhecimento por parte dos melhoristas do potencial dos recursos genéticos disponíveis nos bancos de germoplasma (Morales et al., 1997).

Desta forma, os bancos de germoplasma são importantes ferramentas em programas de melhoramento genético de plantas e devem ser utilizados, como neste caso, como fontes de genes para conferir resistência a doenças em cultivares comerciais de tomateiro. Assim, a Universidade Federal de Viçosa, com apoio da Fundação Rockefeller, criou oficialmenteem 1966 o Banco de Germoplasma de Hortaliças da Universidade Federal de Viçosa (BGH - UFV), sendo o mais antigo da América Latina (SILva et al., 2001).

Além do aspecto informativo, a caracterização e avaliação dos recursos genéticos de um banco de germoplasma têm caráter estratégico, pois segundo a Convenção Internacional de Direitos de Recursos Genéticos (JARAMILLO; BAENA, 2000), para que um país tenha a posse assegurada de determinado recurso genético, é fundamental que este recurso esteja devidamente caracterizado e avaliado.

Desta forma, este trabalho teve como objetivo caracterizar 49 subamostras de tomateiro do BGH-UFV quanto à resistência à pinta preta do tomateiro, visando disponibilizar genes úteis para serem utilizados em programas de melhoramento genético da cultura.

\section{MATERIAL E MÉTODOS}

O experimento foi conduzido na Horta de Pesquisas da UFV, em Viçosa, MG, localizado em latitude $20^{\circ} 45^{\prime} \mathrm{S}$ e longitude $40^{\circ} 38^{\prime} \mathrm{W}$, com altitude de 690 metros. O período do ensaio foi de dezembro de 2007 a abril de 2008. Os dados médios mensais de precipitação e temperaturas máxima, mínima e média podem ser encontrados na Tabela 1.

Foram utilizadas 49 subamostras de tomateiro do BGH-UFV, além dos cultivares Débora, Fanny, IPA-6 e Santa Clara como testemunhas. O cultivar IPA-6 foi considerado o padrão de resistência à pinta preta (Jesus JúnIOR; KUROZAWA, 1996; MORETTO; Barreto, 1997; Tófoli; Kurozawa, 1993). Para padrão de suscetibilidade utilizou-se as cultivares Débora, Fanny e Santa Clara (Tófoli; Kurozawa, 1993). As subamostras utilizados foram BGH-2087, BGH-2088, BGH-2089, BGH-2091, BGH-2092, BGH2093, BGH-2095, BGH-2096, BGH-2097, BGH-2098, BGH-2100, BGH-2102, BGH-2105, BGH-2109, BGH-2110, BGH-2111, BGH-2114, BGH-2115, BGH2116, BGH-2117, BGH-2118, BGH-2120, BGH-2121, BGH-2122, BGH-2124, BGH-2125, BGH-2127, BGH2128, BGH-2131, BGH-2132, BGH-2133, BGH-2134, BGH-2135, BGH-2138, BGH-2141, BGH-2142, BGH2143, BGH-4310, BGH-4349, BGH-4350, BGH-4474, BGH-4512, BGH-4541, BGH-4544, BGH-4546, BGH4547, BGH-4577, BGH-4596 e BGH-4619. Todas as subamostras utilizadas pertencem à espécie Solanum lycopersicum.

O ensaio foi estabelecido sob delineamento de blocos ao acaso, com três repetições e cinco plantas por parcela, sendo três as plantas úteis. As mudas foram produzidas em bandejas de poliestireno expandido de 128 células contendo substrato comercial. O transplantio foi realizado quando as plantas possuíam quatro folhas definitivas, aos 25 dias após a semeadura. Osolo foi arado, gradeado e corrigido de acordo com as recomendação de Ribeiro et al. (1999).

A cultura foi conduzida em espaçamento de 0,60 $\mathrm{m}$ entre plantas e 1,00 m entre linhas com uma haste e tutoramento vertical com fitilho. Os tratos culturais foram realizados semanalmente, assim como as adubações de cobertura. A irrigação foi por aspersão, aumentando a umidade local e potencializando o processo epidemiológico da doença. 
Tabela 1 - Média mensal de precipitação e temperaturas máxima, mínima e média no período de condução do ensaio. Viçosa, MG, 2008.

\begin{tabular}{lcccc}
\hline Mês/Ano & Precipitação $(\mathrm{mm})$ & $\begin{array}{c}\text { Temperatura } \\
\text { máxima }\left({ }^{\circ} \mathrm{C}\right)\end{array}$ & $\begin{array}{c}\text { Temperatura } \\
\text { mínima }\left({ }^{\circ} \mathrm{C}\right)\end{array}$ & $\begin{array}{c}\text { Temperatura } \\
\text { média }\left({ }^{\circ} \mathrm{C}\right)\end{array}$ \\
\hline Dezembro/2007 & 244,9 & 29,4 & 18,6 & 21,3 \\
Janeiro/2008 & 196,9 & 27,4 & 18,2 & 22,1 \\
Fevereiro/2008 & 148,8 & 28,9 & 19,0 & 22,3 \\
Março/2008 & 120,6 & 28,1 & 18,6 & 21,8 \\
Abril/2008 & 49,9 & 27,6 & 17,9 & 20,0 \\
\hline
\end{tabular}

Para a obtenção da solução inoculante, folhas com sintomas da doença foram coletadas em diferentes áreas de plantio e submetidas ao isolamento de propágulos de A. solani no laboratório do Departamento de Fitopatologia da Universidade Federal de Viçosa (DFP-UFV). Após o isolamento e a identificação, o patógeno foi cultivado conforme descrito por FoOLAD et al. (2000) e caracterizado quanto à patogenicidade em folhas destacadas de tomateiro com 45 dias de idade. A seleção dos cinco isolados utilizados no presente trabalho se baseou na agressividade do patógeno.

Os cinco isolados foram cultivados separadamente em meio de cultura BDA, a $25 \pm 2^{\circ} \mathrm{C}$ e fotoperíodo de 12 horas. No sétimo dia de incubação adicionou-se $15 \mathrm{~mL}$ de água destilada em cada placa e com auxílio de um pincel realizou-se ferimentos no fungo com a retirada do micélio. As placas foram mantidas sob estímulo de esporulação sem tampa a $25 \pm 2^{\circ} \mathrm{C}$ e fotoperíodo de 12 horas de luz negra por 60 horas após a retirada do micélio. Após esse tempo, os conídios foram removidos com adição de $10 \mathrm{~mL}$ de água destilada a cada placa e raspagem superficial com escova de dente de cerdas macias. Em seguida, a suspensão foi submetida à filtragem em dupla camada de gaze esterilizada.

As plantas foram inoculadas 45 dias após o transplantio com auxílio de um pulverizador costal manual de $5 \mathrm{~L}$, promovendo cobertura total das plantas. Utilizou-se uma suspensão de $10^{4}$ conídios/ $\mathrm{mL}$, constituída por uma mistura dos já referidos isolados. Não foi utilizado nenhum fungicida após a inoculação. Foram realizadas cinco avaliações, sendo a primeira 48 horas após a inoculação e as outras a cada três dias.

O critério avaliado foi a severidade da doença, que é a resultante do tamanho e número de lesões, sendo que esses dois componentes podem atuar independentemente durante o progresso da doença (Boff et al., 1991). Considerou-se a porcentagem de área foliar lesionada de acordo com Horsfall; Barrat (1945), onde 0 significa $0 \%$ de área foliar lesionada e 100 significa $100 \%$ de área foliar lesionada pelo patógeno. Logo, a porcentagem de desfolha e o número de folhas infectadas da planta podem ser analisados como consequência direta da maior ou menor suscetibilidade de uma mesma planta.

As avaliações foram feitas por três avaliadores, treinados de acordo com o programa Severity Pro 1.0 (NutTer; LitWILler, 1998), sendo que foram avaliadas três plantas previamente marcadas de cada parcela. Todas as folhas de cada planta foram avaliadas. Em seguida, fez-se a média das notas de cada folha da mesma planta em relação aos três avaliadores. A determinação da severidade de cada planta foi feita em função da média de todas as folhas da planta. Posteriormente, os valores de severidade foram utilizados no cálculo da área abaixo da curva de progresso da doença (AACPD), segundo modelo proposto por CAMPBELL; MADDEN (1990).

$$
A A C P D=\sum_{1}^{n-1} \frac{(Y i+Y i+1)}{2}(t i+1-t i)
$$

Onde, $n$ é o número de avaliações, $y$ a severidade expressa em porcentagem e $t$ é o período de tempo empregado nas avaliações, expresso em dias.

Os dados de AACPD foram submetidos à análise de variância e as médias dos genótipos foram agrupadas pelo teste de Scott-Knott, a 5\% de probabilidade, com auxílio do programa GENES (CRUZ, 1997).

\section{RESULTADOS E DISCUSSÃO}

Com os dados da reação dos genótipos representados pela área abaixo da curva de progresso da doença, verificou-se diferença significativa entre as subamostras de tomateiro do BGH-UFV (Tabela 2) evidenciando assim variabilidade genética entre estas. Os dados foram convertidos em AACPD, uma vez que a melhor representação de uma epidemia é a curva de progresso da doença (Paula; Oliveira, 2003). Esta opção também pode auxiliar na avaliação de estratégias de controle, previsão de níveis futuros de doença. 
Tabela 2 - Médias de AACPD para 49 subamostras de tomateiro do Banco de Germoplasma de Hortaliças da UFV e quatro cultivares comerciais, avaliados quanto à resistência a Alternaria solani. Viçosa, MG, 2008.

\begin{tabular}{lcll}
\hline Subamostra & AACPD & Subamostra & AACPD \\
\hline Fanny & $104,2647 \mathrm{~A}$ & BGH-2097 & $72,8779 \mathrm{~L}$ \\
BGH-4512 & $99,4585 \mathrm{~B}$ & BGH-4474 & $72,7085 \mathrm{~L}$ \\
BGH-2141 & $99,4554 \mathrm{~B}$ & BGH-2087 & $72,3611 \mathrm{~L}$ \\
BGH-2125 & $97,5556 \mathrm{C}$ & BGH-2102 & $71,8889 \mathrm{~L}$ \\
Débora & $96,7503 \mathrm{D}$ & BGH-2143 & $70,2778 \mathrm{M}$ \\
BGH-2133 & $95,7228 \mathrm{D}$ & BGH-4350 & $70,0000 \mathrm{M}$ \\
BGH-2089 & $94,6945 \mathrm{D}$ & BGH-2105 & $69,7917 \mathrm{M}$ \\
BGH-2132 & $92,9445 \mathrm{E}$ & BGH-2117 & $69,6250 \mathrm{M}$ \\
BGH-2124 & $90,7083 \mathrm{~F}$ & BGH-4546 & $69,1252 \mathrm{M}$ \\
BGH-2138 & $88,8335 \mathrm{G}$ & BGH-2116 & $67,3472 \mathrm{~N}$ \\
BGH-2118 & $87,5139 \mathrm{G}$ & Santa Clara & $66,6807 \mathrm{~N}$ \\
BGH-4541 & $87,2224 \mathrm{G}$ & BGH-4544 & $64,9724 \mathrm{O}$ \\
BGH-2093 & $86,2084 \mathrm{G}$ & BGH-2131 & $64,5972 \mathrm{O}$ \\
BGH-4310 & $84,8751 \mathrm{H}$ & BGH-2128 & $63,9585 \mathrm{O}$ \\
BGH-2096 & $83,6110 \mathrm{H}$ & BGH-2098 & $63,9584 \mathrm{O}$ \\
BGH-4547 & $83,4167 \mathrm{H}$ & BGH-4619 & $63,5418 \mathrm{O}$ \\
BGH-2095 & $83,1667 \mathrm{H}$ & BGH-2120 & $63,3056 \mathrm{O}$ \\
BGH-4596 & $83,1112 \mathrm{H}$ & BGH-2127 & $60,7083 \mathrm{P}$ \\
BGH-2091 & $80,6250 \mathrm{I}$ & Ipa-6 & $59,3501 \mathrm{P}$ \\
BGH-2100 & $80,2223 \mathrm{I}$ & BGH-2134 & $57,7389 \mathrm{Q}$ \\
BGH-2088 & $79,6250 \mathrm{I}$ & BGH-2110 & $57,5140 \mathrm{Q}$ \\
BGH-2092 & $78,1249 \mathrm{~J}$ & BGH-2135 & $57,2777 \mathrm{Q}$ \\
BGH-4349 & $77,3640 \mathrm{~J}$ & BGH-2122 & $56,2500 \mathrm{Q}$ \\
BGH-2111 & $76,8333 \mathrm{~J}$ & BGH-2109 & $55,7223 \mathrm{Q}$ \\
BGH-2121 & $76,5278 \mathrm{~J}$ & BGH-2142 & $51,3610 \mathrm{R}$ \\
BGH-4577 & $74,5280 \mathrm{~K}$ & BGH-2115 & $51,1667 \mathrm{R}$ \\
BGH-2114 & $74,2639 \mathrm{~K}$ & & \\
\hline
\end{tabular}

Grupos de médias seguidas pela mesma letra na coluna não diferem entre si pelo teste de Scott-Knott, a 5\% de probabilidade.

Coeficiente de Variação $=14,72 \%$.

O período de condução deste ensaio foi caracterizado por condições de altas temperaturas e umidade (Tabela 1). Relatos feitos na literatura sobre o efeito das condições climáticas no desenvolvimento da pinta preta do tomateiro sugerem que epidemias severas ocorrem com maior frequência sob condições de temperaturas maiores que $25^{\circ} \mathrm{C}$ associadas a altas umidades (Jones et al., 1991; Maffia et al., 1980; Rotem, 1994). Além disso, a umidade favorece a esporulação de $A$. solani que aumenta à medida que a temperatura aumenta para $27^{\circ} \mathrm{C}$ durante o período de molhamento foliar (SHERF; MACNAB, 1986).

Os genótipos com as menores médias de AACPD foram BGH-2115 e BGH-2142. No entanto, as subamostras BGH-2109, BGH-2110, BGH-2115, BGH-2122, BGH2134, BGH-2135 e BGH-2142 apresentaram médias de AACPD inferiores ao padrão de resistência IPA-6 (TóFOLI; Kurozawa, 1993; Moretto; Barreto, 1997; Jesus Júnior;
Kurozawa, 1996). O cultivar Santa Clara apresentou AACPD 66,6807 enquanto que Paula; Oliveira (2003) encontraram em trabalho semelhante para a mesma cultivar uma AACPD de 484,33. No entanto, o método de quantificação da doença utilizado por PAULA; OliveIrA (2003) foi diferente, podendo explicar a diferença nos resultados obtidos.

Nas avaliações realizadas observou-se que a partir da inoculação a doença manifestou seus sinais na planta, acentuando-se gradativamente em algumas subamostras. A maioria dos genótipos caracterizados como resistentes em condições laboratoriais não apresentam tal comportamento em condições de campo (FoOLAD et al., 2000; MAIERo et al., 1989). Portanto, estudos em condições de campo, como o presente trabalho, são mais indicados para avaliações de resistência de plantas, sendo mais fiéis aos resultados encontrados (FoOLAD et al., 2000). 
Alguns trabalhos mostram que subamostras de tomateiro com níveis de resistência maiores do que os encontrados no mercado vêm sendo utilizadas em programas de melhoramento, promovendo o desenvolvimento de cultivares com níveis elevados de resistência ao patógeno (Barksdale; Stoner, 1973; Gardner, 1988; Gardner; Shoemaker, 1999; NAsh; GARDNER, 1988). Desta forma, as subamostras BGH-2109, BGH-2110, BGH-2115, BGH2122, BGH-2134, BGH-2135 e BGH-2142 podem ser utilizadas como fonte de genes em possíveis programas de melhoramento.

\section{CONCLUSÃO}

As subamostras BGH-2109, BGH-2110, BGH-2115, BGH-2122, BGH-2134, BGH-2135 e BGH-2142 podem ser utilizadas como fontes de genes em programas de melhoramento genético do tomateiro à Alternaria solani.

\section{AGRADECIMENTOS}

À FAPEMIG, pela concessão da bolsa de iniciação científica e à UFV por conceder toda a infraestrutura necessária.

\section{REFERÊNCIAS}

BARKSDALE, T.H.; STONER, A.K. Segregation for horizontal resistance to tomato early blight. Plant Disease Report, v.57, p.964-964, 1973.

BATISTA, D.C.; LIMA, M.A.; HADDAD, F.; MAFFIA, L.A.; MIZUBUTI, E.S.G. Validation of decision support systems for tomato early blight and potato late blight, under Brazilian conditions. Crop Protection, v.25, p.664670, 2006.

BOFF, P.; ZAMBOLIM, L.; VALE, F.X.R. Escalas para avaliação de severidade da mancha-de-estenfílio (Stemphylium solani) e da pinta preta (Alternaria solani) em tomateiro. Fitopatologia Brasileira, v.16, p.280-283, 1991.

CAMPBELL, C.L.; MADDEN, L.V. Introduction to plant disease epidemiology, New York: John Wiley, 1990. $532 \mathrm{p}$.

CHAERANI, R.; GROENWOLD, R.; STAM, P.; VOORRIPS, R.E. Assessment of early blight (Alternaria solani) resistance in tomato using a drop inoculation method. Journal of General Plant Pathology, v.73, n.2, p.96-103, 2007.

CRUZ, C.D. Programa Genes - aplicativo computacional em genética e estatística, Viçosa: Editora UFV, 1997. $442 \mathrm{p}$.
FOOLAD, M.R.; NTAHIMPERA, N.; CHRIST, B.J.; LIN, J.Y. Comparison of field, greenhouse, and detachedleaflet evaluations of tomato germoplasm for early blight resistance. Plant Disease, v.84, n.9, p.967-972, 2000.

FREITAS FILHO, A.M.; SANTOS, S.S.; FILHO, J.U.T.B.; SANTOS, H.S.; VIDA, J.B.; HORA, R.C. Controle da pinta preta (Alternaria solani) por meio de fungicidas na cultura do tomate. Horticultura Brasileira, v.26, n.2, p.2922-2926, 2008.

FRITZ, M.; JAKOBSEN, I.; LYNGKJAER, M.F.; CHRISTENSEN, H.T.; KÜHNEMANN, J.P. Arbuscular mycorrhiza reduces susceptibility of tomato to Alternaria solani. Mycorrhiza,v.16, n.6, p.413-419, 2006.

GARDNER, R.G. NC EBR-1 and NC EBR-2 early blight resistant tomato breeding lines. HortScience, v.23, p.779781, 1988.

GARDNER, R.G.; SHOEMAKER, P.B. 'Mountain Supreme' early blight resistant hybrid tomato and its parents, NC EBR-3 and NC EBR-4. HortScience, v.34, p.745-746, 1999.

HOLM, A.L.; RIVERA, V.V.; SECOR, G.A.; GUDMESTAD, N.C. Temporal sensitivity of Alternaria solani to foliar fungicides. American Journal of Potato Research, v.80, p.33-40, 2003.

HORSFALL, J.G.; BARRATT, R.Q. An improved grading system for measuring plant diseases. Phytopathology, v.35, p.655, 1945.

IBGE. INSTITUTO BRASILEIRO DE GEOGRAFIA E ESTATÍSTICA. Levantamento sistemático da produção agrícola. 2010. Disponível em: <http:/ / www.sidra.ibge.gov. $\mathrm{br} / \mathrm{bda} /$ tabela $/$ listabl.asp?c $=1618 \& \mathrm{z}=\mathrm{t} \& \mathrm{o}=3>$. Acesso em 19 set. 2010.

ITAKO, A.T.; SCHWAN-ESTRADA, K.R.F.; TOLENTINO JÚNIOR, J.B.; STANGARLIN, J.R.; CRUZ, M.E.S. Atividade antifúngica e proteção do tomateiro por extratos de plantas medicinais. Tropical Plant Pathology, v.33, n.3, p.241-244, 2008.

JARAMILLO, S.; BAENA, M. Conservación ex situ de recursos fitogenéticos. Roma: International Plant Genetic Resources Institute, 2000. 109p.

JESUS JÚNIOR, W.C.; KUROZAWA, C. Comportamento de híbridos, cultivares, novas introduções, e espécies selvagens de tomateiro à pinta preta. Summa Phytopathologica, v.22, n.1, p.137-140, 1996.

JONES, J.B.; JONES, J.P.; STALL, R.E.; ZITTER, T.A. Compendium of tomato diseases. Saint Paul: APS Press, 1991. 110p.

MAFFIA, L.A.; MARTINS, M.C.P.; MATSUOKA, K. Doenças do tomateiro. Informe Agropecuário, n.6, p.42-60, 1980. 
MAIERO, M.; NG, T.J.; BARKSDALE, T.H. Combining ability estimates for early blight resistance in tomato. Journal of the American Society for Horticultural Science, v.114, n.1, p.118-121, 1989.

MORALES, E.A.V.; VALOIS, A.C.C.; NASS, L.L. Recursos genéticos vegetables. Brasília: SPI, 1997. 79p.

MORETTO, K.C.K.; BARRETO, M. Efeito do critério de avaliação na determinação de resistência de tomateiro à pinta preta. Summa Phytopathologica, v.23, n.1, p.228-231, 1997.

NASH, A.F.; GARDNER, R.G. Tomato early blight resistance in a breeding line derived from Lycopersicon esculentum PI 126445. Plant Disease, v.72, n.3, p.206-209, 1988.

NUTTER, F.W.; LITWILLER, D. Programa severity pró 1.0. Iowa State University, 1998.

PATTERSON, J.M.; NOKES, S.E. Incorporation of chlorothalonil persistence on processing tomato into TOMCAST. Agricultural Systems, v.64, n.3, p.171-187, 2000.

PAULA, R.S.; OLIVEIRA, W.R. Resistência de tomateiro (Lycopersicon esculentum) ao patógeno Alternaria solani. Pesquisa Agropecuária Tropical, v.33, n.2, p.89-95, 2003.

RIBEIRO, A.C.; GUIMARÃES, P.T.G.; ALVAREZV, V.H. Recomendações para o uso de corretivos e fertilizantes em Minas Gerais: $5^{a}$ Aproximação. Viçosa: Editora UFV, 1999. 359p.

ROTEM, J. The genus Alternaria: biology, epidemiology and pathogenicity. Saint Paul: APS Press, 1994. 326p.

SCHUELTER, A.R.; MAROCHIO, J.; SOUZA, C.S.; PHILIPPSEN, C.C.O.; HECK, M.C.; LANNES, S.D.; SCHUSTER, I; FINGER, F.L.; SOUZA, I.R.P. Genetic control os modified genomic region in a firm ripening tomato (Lycopersicon esculentum Mill.) mutant. Crop Breeding and Applied Biotechnology, v.6, n.4, p.261-268, 2006.
SHERF, A.F.; MacNAB, A.A. Tomato. In: (Ed.). Vegetables diseases and their control. New York: John Wiley, 1986. p.599-696.

SILVA, D.J.H.; MOURA, M.C.; CASALI, V.W.D. Banco de germoplama de Hortaliças - UFV: histórico e conteúdo. Horticultura Brasileira, v.19, n.2, p.108-114, 2001.

TAMBARUSSI, E.V.; MELOTTO-PASSARIN, D.M.; GONZALEZ, S.G.; BRIGATI, J.B.; JESUS, F.A.; BARBOSA, A.L.; DRESSANO, K.; CARRER, H. In silico analysis of Simple Sequence Repeats from chloroplast genomes of Solanaceae species. Crop Breeding and Applied Biotechnology, v.9, n.4, p.344-352, 2009.

TÓFOLI, J.G.; DOMINGUES, R.J. Controle da pinta preta do tomateiro com o uso de acibenzolar-s-metil isolado, em mistura com fungicidas e em programas de aplicação. Arquivos do Instituto Biológico, São Paulo, v.72, n.4, p.481-487, 2005.

TÓFOLI, J.G.; KUROZAWA, C. Avaliação da resistência de cultivares e híbridos de tomateiro à pinta preta (Alternaria solani). Summa Phytopathologica, v.19, n.1, p.39-40, 1993.

VALE, F.X.R.; ZAMBOLIM, L.; CHAVES, G.M. Avaliação fitossanitária da cultura do tomateiro em regiões produtoras de Minas Gerais e Espírito Santo. Fitopatologia Brasileira, v.17, n.2, p.211, 1992.

VALLOIS, A.C.C. Genética aplicada a recursos fitogenéticos. Brasília: Editora UNEB, 1998. 318p.

VALLOIS, A.C.C.; SALOMÃO, A.N.; ALLEM, A.C. Glossário de recursos genéticos vegetais. Brasília: SPI, 1996. $62 \mathrm{p}$.

Recebido em 20/10/10

Aceito em 24/10/11 